\title{
Fotografía móvil y redes sociales: Prácticas de producción y socialización en jóvenes universitarios
}

\section{Mobile Photography and Social Networks: Production and Socialization among University Students}

\author{
Jacob Bañuelos \\ Director de la Maestría en Comunicación (MCO) y profesor e Investigador de \\ Tiempo Completo Departamento de Estudios Culturales \\ (Tecnológico de Monterrey, México)
}

Fecha de recepción: 28 de julio de 2016

Fecha de revisión: 31 de octubre de 2016

Para citar este artículo: Bañuelos, J. (2017): Fotografía móvil y redes sociales: Prácticas de producción y socialización en jóvenes universitarios, Icono 14, volumen 15 (1), pp. 1-22. doi: 10.7195/ri14.v14i2.999 


\section{ARTÍCULOS DE INVESTIGACIÓN}

\section{Resumen}

El presente estudio analiza los resultados de una exploración sobre prácticas de producción, consumo, socialización, privacidad y derechos de autor que realiza una muestra de 93 jóvenes universitarios mexicanos del Tecnológico de Monterrey-Ciudad de México, que estudian las carreras de Comunicación y Medios Digitales, Mercadotecnia Digital, Animación y Arte Digital. El estudio explora cómo estos nativos digitales usan los dispositivos móviles en sus prácticas de consumo, socialización y producción fotográfica en las redes sociales, mediante qué aplicaciones y qué conceptos tienen sobre privacidad y derechos de autor. El estudio revela una clara tendencia en los jóvenes a adquirir una progresiva cultura snapr frente a una cultura kodak.

Palabras clave: Fotografia móvil - Producción - Consumo - Socialización - Privacidad - Derechos de autor - Redes sociales

\section{Abstract}

The present study analyzes the results of an exploration of practices of production, consumption, socialization, privacy and copyrights in a sample of 93 young Mexican university students from Tecnológico de Monterrey-Mexico City, who study Communication and Digital Media, Digital Marketing, And Animation and Digital Art. The study explores how these digital natives use mobile devices in their practices of consumption, socialization and photographic production in social networks, through which applications and what concepts they have about privacy and copyright. The study reveals a clear trend in young people to acquire a progressive culture snapr against a kodak cultures.

Key Words: Mobile photography - Production - Consumption - Socialization - Privacy - Copyright - Social networks 
Fotografía móvil y redes sociales: Prácticas de producción y socialización... 3

ARTÍCULOS DE INVESTIGACIÓN

\section{Introducción}

En el contexto contemporáneo la práctica fotográfica realizada mediante dispositivos móviles se encuentra expuesta a cambios constantes y significativos, que dan lugar a la emergencia de nuevas formas de producir, consumir, socializar y enfrentar las problemáticas sobre derechos de autor de la imagen fotográfica.

Es por ello que el presente estudio tiene como objetivo explorar las prácticas fotográficas que realiza una muestra de 93 jóvenes universitarios mexicanos en edades comprendidas entre los 19 y 25 años, usuarios habituales de smartphones, y dedicados al estudio de la Comunicación, los Medios Digitales, la Mercadotecnia Digital, la Animación y el Arte Digital.

En 2010 se emprendió una primera aproximación sobre las competencias fotográficas en nativos digitales, con el fin de conocer las prácticas de producción, consumo, socialización, conocimiento sobre derechos de autor, prácticas culturales y competencias fotográficas de una muestra similar a la del estudio presente. El estudio se titula, Photography 2.0: Competences and cultural practices (Bañuelos, J., 2011).

El estudio presente explora igualmente las prácticas de producción, consumo, socialización y conocimiento sobre derechos de autor, pero está más centrado a conocer estás prácticas en el entorno de los teléfonos móviles y en el uso de las redes sociales empleadas por estos jóvenes.

Ambos estudios permiten vislumbrar y comparar cambios significativos en el escenario del uso de la fotografía debido al empleo cada vez más habitual de smartphones con acceso a Internet, la aparición de aplicaciones móviles dedicadas a la fotografía y la emergencia de redes sociales visuales como Instagram, que en 2010 recién nacían o no existían. De esta forma, subrayaremos algunas comparaciones significativas entre ambos estudios.

La pregunta eje que guía el presente estudio es ¿Cómo es la práctica de producción, consumo, socialización y derechos de autor de la fotografía móvil y redes sociales en jóvenes universitarios mexicanos dedicados al estudio de la comunicación y la imagen? 


\subsection{Contexto}

En México ha crecido de manera significativa el uso de teléfonos móviles y de smartphones con acceso a Internet en años recientes. El estudio realizado anualmente por la Asociación Mexicana de Internet (AMIPCI, 2015) sobre hábitos de consumo de Internet, revela los siguientes datos sobre 2015:

- La población conectada a Internet en México alcanzó el 51\% de penetración sobre el universo de personas potencialmente usuarias (mayores de 6 años). La cifra absoluta llegó a 53.9 millones de usuarios, con un crecimiento de $5.3 \%$ contra las cifras del estudio anterior

- El $37 \%$ son personas entre $19-34$ años de edad y el $50 \%$ son hombres y $50 \%$ mujeres

- El 27\% de los usuarios habitan el Centro del país, y la menor densidad se da en el Sur y Sureste (6 y $5 \%$ respectivamente). El Noroeste aloja a un 15\% y en las demás regiones la población internauta se distribuye en porcentajes entre el $11 \mathrm{y}$ el $13 \%$

- Se presenta un incrementando en el tiempo de exposición a Internet, con un promedio de 6 horas y 11 minutos diariamente, 24 minutos más que las 5 horas 36 minutos del año pasado

- La gran mayoría se conecta a Internet desde el hogar (84\%) al igual que el año pasado, seguido por el sitio de trabajo (42\%). Destaca que la escuela detuvo su tendencia de reducción de ediciones anteriores, y ahora superó las cifras del año pasado con un 36\%, (34\% de 2013).

- Las conexiones a través de una señal WiFi contratada mostraron un crecimiento de $14 \%$ ( $66 \%$ en $2014,80 \%$ en 2015 )

- El segmento de los smartphones creció de $49 \%$ a $58 \%$, desplazando a la computadora de escritorio a un tercer lugar (54\%) 
Fotografía móvil y redes sociales: Prácticas de producción y socialización... 5 ARTÍCULOS DE INVESTIGACIÓN

- El $87 \%$ de los usuarios de un smartphone navega por Internet, el 79\% hace búsquedas de información y el 77\% recibe y envía correos electrónicos. En proporciones cercanas al 50\%, revisan archivos, leen noticias y descargan material multimedia (música, fotos, videos)

- El $82 \%$ de los internautas ha descargado e instalado apps en su teléfono celular inteligente

- Por primera vez en la historia, las redes sociales toman la vanguardia con un 85\% de los internautas (en 2014 el uso principal era el correo electrónico), seguido por las búsquedas de Información (78\%) y hasta el tercer lugar, el correo electrónico con un $73 \%$

- $93 \%$ de los internautas mexicanos tienen al menos una cuenta en alguna red social

La muestra de jóvenes explorada en el presente estudio se encuentra bien representada en la cifras de contexto de la sociedad mexicana, dadas la cualidades de la muestra de AMPCI (2015) que explora un $47 \%$ de población de clase alta y media alta, a la cual pertenece nuestra muestra.

\subsection{Estudios Previos}

Asistimos a una auténtica explosión de estudios relacionados con el consumo de la fotografía móvil, redes sociales e Internet, que crece exponencialmente en el mundo académico y en el ámbito internacional.

De esta forma, encontramos obras de referencia que enmarcan una reflexión global sobre prácticas de uso de Internet, y una enorme gama de estudios de exploración aplicada que abordan las prácticas de la telefonía móvil y la fotografía en redes sociales que analizan el fenómeno desde diversas perspectivas disciplinarias y se enfocan en estudiar aspectos tecnológicos, participativos, identitarios, patrones culturales, estéticos, etnográficos y de comportamiento. 


\section{ARTÍCULOS DE INVESTIGACIÓN}

El escenario de estudios previos es vasto, por lo que citamos sólo algunos estudios útiles para guiar y enmarcar el presente trabajo. Del mismo modo, sirven estas referencias como estado del arte del tema que nos ocupa.

Como hemos mencionado, en 2010 realizamos un estudio similar al presente titulado Photography 2.0: Competences and cultural practices (Bañuelos, J., 2011), centrado en conocer las prácticas de producción, organización de archivos, socialización, privacidad y derechos de autor (Bañuelos, J., 2011), que tiene una metodología idéntica, con una muestra de estudiantes muy similar y que nos sirve para comparar algunos aspectos relevantes sobre el estado del arte y sobre la cultura fotográfica móvil, cinco años después.

Algunos referentes teóricos que usamos para el estudio de 2010 y que siguen siendo útiles para comprender un marco general sobre el uso de la telefonía y la comunicación móvil son Castells (2007) con su Comunicación móvil y sociedad, su Comunicación y poder (2009), y su Sociedad Red. La era de la información, economía, sociedad y cultura (2006). Más recientemente ha reflexionado sobre el poder de las redes y el papel de los móviles en los movimientos sociales y la democracia, en Democracy in the age of the Internet (Castells, 2011).

Más reciente, el estudio de Van Dijck (2008), Digital photography: Communication, identity, memory, en el que analiza la transformación en las prácticas individuales y sociales que trae consigo la digitalización y la instantaneidad en la fotografía así como su impacto en la creación de identidad y memoria virtual. Thompson (2005), en 2005 analiza los efectos relativos a la imagen y la interacción en torno a la guerra de Irak, en su The New Visiblity.

Encontramos de Nov, Naaman, Ye (2008), Community photo sharing: Motivational and structural antecedents, un estudio en donde proponen un modelo de intercambio fotográfico digital, basado en dos grandes campos, las motivaciones individuales y las relaciones comunitarias estructurales; Counts y Fellheimer (2004), exploran el incremento del intercambio fotográfico sobre eventos de la vida cotidiana, mediante una aplicación creada para el teléfono móvil, Flipper, similar a Snapfish; House y Davis (2005) The Social Life of cameraphone images, en el que 
Fotografía móvil y redes sociales: Prácticas de producción y socialización... 7 ARTÍCULOS DE INVESTIGACIÓN

exploran los usos de las imágenes mediante el Mobile Media Metadata 2, un sistema de intercambio de fotos mediante el teléfono, las cuales son: memoria, socialización, auto-presentación, expresión personal, usos funcionales y documentalismo.

Sarvas y Lehmuskallio (2008), Snapshot media: "Kodak culture" in the 21st Century, formulan el término snapshot media, y concluyen que las procesos fotográficos de captura, producción y socialización digitales, excluyen a las viejas generaciones y a grupos no familiarizados con las tecnologías digitales. Miller-0tt, A. E., Kelly, L., \& Duran, R. L. (2012), estudian las reglas de satisfacción en relaciones amorosas establecidas mediante fotografías compartidas mediante móviles.

La London School of Economics and Political Science. (LSE, 2013) publicó recientemente un compendio útil de estudios realizados entre 2002 y 2012 en Mobile VIsual References, del Department of Media and Communications. Otro compendio interesante para abordar los estudios sobre el selfie los reúne Gaby Daviden su The selfie research network (David, 2014).

Otros estudios contemporáneos sobre consumo y socialización fotográfica mediante móviles están caracterizados por reunir perspectivas diversas en entornos globalizados y más centrados en el uso de redes sociales como Hand, Martin, (2012), bajo el concepto de la fotografía ubícua; Sarvas, R., Frohlich, D. (2011), acerca del uso de snapshots en redes sociales, analizando los cambios de la fotografía doméstica; Araya, D., Breindl, Y., Houghton, T. (2011), Nov, 0., Naaman, Mor., Ye, Ch. (2009), acerca de la participación y socialización comunitaria en línea desde una perspectiva multidimensional.

Estudios de mayor alcance regional están bien representados por Yan, S. (2015), quien coordina una enciclompedia de estudios sobre el compartamiento con smartphones, y los estudios de Hjorth, L $(2012,2010,2019)$, sobre prácticas fotográficas con cámaras en móviles, prácticas artísticas, photo shopping, y el impacto cultural de la tecnología móvil (larissahjorth.net/list-of-publications/).

De Lev Manovich y Nadav Hochman $(2013,2012,2009)$ (Software Studies Initiative) destacamos dos proyectos de investigación ejemplares Phototrails (http:// 


\section{ARTÍCULOS DE INVESTIGACIÓN}

phototrails.net/ 2013) y Selfiecity (http://selfiecity.net/\#, 2014), en donde se analizan millones de fotos y selfies en redes sociales como Instagram mediante análisis de metadatos (Big visual data y "fragmented images") para establecer patrones estéticos y culturales en las fotografías de los usuarios.

\section{Marco Teórico}

Para el análisis de las prácticas de la fotografía móvil y las redes sociales del presente estudio, retomamos dos categorías conceptuales básicas que nos permitirán analizar las tendencias de producción, consumo, socialización, privacidad y derechos de autor de nuestra muestra.

La primer categoría, los kodakrs está formulada por Chalfen (1987), Snapshot versions of life, en su estudio fundacional sobre las competencias tecnológicas y prácticas culturales de los fotógrafos aficionados en lo que el autor denomina la "Cultura Kodak" y de lo que se desprende llamar a los usuarios de esta cultura fotográfica: kodakrs, centrados en el uso de la fotografía como relato, para dar cuenta de la cotidianidad y de la vida privada principalmente para reforzar los vínculos emocionales entorno a la familia y los amigos.

Richard Chalfen (1987) realiza estudios de campo con un abanico de familias norteamericanas para explorar las prácticas de consumo, socialización y producción en el uso de la cámara fotográfica y la cámara Super 8, revelando que los usuarios utilizan la fotografía y el film principalmente para formar una memoria familiar que permita construir una narrativa histórica propia, que tiene como objetivo preservar la experiencia y fortalecer los lazos de la vida emocional y familiar en un entorno privado. Las prácticas fotográficas de los kodakrs de acuerdo con Chalfen (1987), no presentan competencias especializadas en el manejo de un equipo fotográfico y usan el archivo fotográfico únicamente como el espacio y soporte de un álbum familiar y emocional.

La segunda categoría conceptual, los snaprs, está formulada por Miller y Edwards $(2012,2007)$, en su Give and take: A study of consumer photo-sharing culture and practice, quienes aportan un análisis comparativo entre usuarios tradicionales 
"migrantes digitales", pertenecientes a la Cultura Kodak, y los nuevos productoresdifusores de la fotografía digital en redes sociales, los snaprs, caracterizados por tener altas competencias tecnológicas en el uso de la fotografía digital, las redes sociales como Flickr, una apertura sobre la socialización de la privacidad en las redes sociales y por compartir casi inmediatamente sus imágenes en una red fotográfica.

Los snaprs usan la fotografía para construir una narrativa compartida en un espacio digital, en donde existe una memoria expandida, en la que las nociones de privacidad y la función de fortalecer lazos familiares han sido también expandidas, transformadas, transgredidas y toman el curso hacia la socialización colectiva y pública de la experiencia a través de las imágenes. Cabe decir que las prácticas de los fotógrafos snapr, presentan en los estudios de Miller y Edwards (2012, 2007), competencias tecnológicas más especializadas, utilizando equipos fotográfcios más profesionales y usando los perfiles de las redes a manera de portafolios de obra y profesionales.

\section{Metodología}

La presente investigación es resultado de una estudio empírico, que explora las competencias tecnológicas y las prácticas culturales en 93 estudiantes universitarios, 64 mujeres y 29 hombres, de una institución educativa privada de la Ciudad de México, específicamente de las carreras de Comuniación y Medios digitales, y Animación y Arte Digital del Tecnológico de Monterrey - Campus Ciudad de México, que pertenecen a clase social media, media alta y alta.

La pregunta central de esta investigación es ¿Cómo usan los jóvenes universitarios mexicanos la fotografía móvil en las redes sociales? Se exploran también otras preguntas secundarias como: ¿Qué dispositivos usan y cuánto invierten en ellos? ¿Qué aplicaciones usan para hacer fotos? ¿Qué redes sociales usan? ¿Qué los motiva a hacer fotos? ¿Qué temas fotografían? ¿Qué hacen con sus fotos? ¿Qué saben sobre privacidad y derechos de autor en las redes sociales? 


\section{ARTÍCULOS DE INVESTIGACIÓN}

Un factor importante para la elección de la muestra fue que debían cursar las clases de Fotografía e Imagen Digital, inscritos en las carreras de Ciencias de la Comunicación, Animación-Arte Digital y Mercadotecnia-Medios Digitales.

Otro factor necesario, al igual que en nuestro estudio previo ya citado, es que fueran "nativos digitales" (Prensky, 2001) (Palfrey, 2008), nacidos entorno a 1990 y que tuvieran entre 19 y 25 años. Otras condiciones más fueron que tuvieran acceso a Internet, que fueran usuarios de alguna red social, que tuvieran cámara digital y usaran teléfono móvil con cámara. No fue un requisito que supieran usar una cámara réflex digital o que tuvieran ya un perfil en algún sitio especializado en fotografía como Flickr.com

Se aplicó una encuesta en la que los estudiantes no debían dar su nombre, con 39 preguntas de opción múltiple, mediante un sistema digital, enviadas a sus correos electrónicos y se dejó abierta un mes para ser contestada. Las preguntas se formularon entorno a seis categorías principales sobre el uso de la fotografía móvil: producción, consumo, socialización, privacidad, derechos de autor y redes sociales fotográficas. El presente estudio es una segunda aproximación al tema, enfatizando la exploración del uso de cámaras en smartphones y redes sociales, que será objeto de futuros acercamientos.

\section{Análisis y resultados}

En seguida se presentan y analizan los resultados de las encuestas con base en las siguientes categorías: producción, consumo, socialización, privacidad, derechos de autor. Y a partir de estos resultados reflexionamos acerca del uso que hacen los estudiantes de la fotografía móvil y las redes sociales.

\subsection{Producción}

En este apartado reunimos los resultados relacionados con la captura de fotografías mediante smartphones, dispositivos, sistema operativo, gasto económico en el consumo del móvil; también exploramos si los alumnos le dan importancia a la calidad de la cámara del dispositivo, frecuencia de captura de fotos, motivos de captura, 
Fotografía móvil y redes sociales: Prácticas de producción y socialización... 11

ARTíCULOS DE INVESTIGACIÓN

temas, uso de aplicaciones, valores de calidad fotográfica. Hemos encontrado que el $62 \%$ de la muestra usa un smartphone, frente al $29 \%$ que usa un teléfono celular sin acceso a la red. Es significativo que la mayoría usa un smartphone y que el 63\% usa sistema operativo Apple (iPhone) frente al 35\% que usa Android. El 35\% gasta entre 500 y 800 pesos (40 dólares aprox.) al mes para mantener los servicios del móvil. Una cifra alta para un estudiante sin ingresos. Al $88 \%$ le interesa la calidad de la cámara del celular, eso podría explicar que la mayoría use un IPhone.

En cuanto a la frecuencia de captura fotográfica, la mayoría, 72\% hace fotos diario o cada dos días y el $20 \%$ una vez a la semana. Encontramos una enorme diferencia con nuestro estudio anterior antes citado, en el que la frecuencia de captura era de una vez a la semana el 38\% de los encuestados y $29 \%$ tres veces por semana. En comparación, ahora el $92 \%$ hacen fotos por lo menos una vez a la semana, un aumento muy significativo.

En cuanto a los principales motivos para hacer fotos aparece en primer lugar como lo más relevante "compartir mi experiencia" con un 34\%, seguido de "expresar mis emociones" y "documentar la realidad" prácticamente empatados con un $23.6 \%$. Contrasta que "hacer amigos" aparece con el $49 \%$ como el motivo menos relevante al momento de hacer fotos.

Sin embargo, el tema más relevante para hacer fotos es "amigos" (9.13 puntos sobre un total de 13), seguido de "viajes" (8.78 puntos) y paisajes (8.68 puntos) $\mathrm{y}$ en tercer nivel de relevancia aparece "objetos de mi entorno" (8.08 puntos), autorretrato (7.71), fiestas (7.69) y familia (7.44). El tema menos fotografiado es "desnudo" (2.66 puntos). Una vez más, al igual que en el estudio anterior, el tema más importante fue "amigos" (50\%), el segundo es "viajes" (45.7\%).

El 74\% cuida los valores de calidad fotográfica como foco, composición, iluminación, color, contraste, volumen, escala, nitidez, barridos, movimiento. El valor que más se cuida es la "composición" con un $42 \%$ de respuestas de mayor relevancia, seguido del "foco" (21\%) e "iluminación" (15.6\%). El valor que menos se cuida es la "escala", valor que nadie considera de mayor relevancia y sólo alcanza un total de 3.27 puntos sobre 10). Al $81 \%$ le interesa que sus fotos tengan "una estética fotográfica determinada". 


\section{ARTÍCULOS DE INVESTIGACIÓN}

El 65\% usa una aplicación para capturar fotografías con el móvil, principalmente empleada para "retoque" (58\%), seguida de una aplicación de "red social" (50\%), y "captura y modificación" (35\%). La aplicación más usada es Instagram (72\%), seguida de Snapchat (31\%) y Snapseed (11\%). En nuestro estudio anterior realizado a finales de 2010, Instagram no existía en el escenario de las aplicaciones móviles, ya que apareció el 6 de octubre de 2010. El uso actual de Instagram en el presente estudio es altamente significativo.

\subsection{Consumo}

En este apartado reunimos los resultados de la exploración sobre qué redes sociales usan los alumnos para visualizar, comentar, conocer qué tipo de fotos ven con mayor frecuencia. Encontramos que la red social que más se usa para ver fotografias es Instagram (49\%), seguida de Facebook (15\%) y Pinterest (13.9\%); las redes menos usadas para ver fotografías son Flickr (5.3\%), Twitter (3.23\%) y 500pixeles (3.23\%). Un dato significativo porque Flickr y 500 pixeles son redes altamente especializadas en fotografía y Twitter, que a pesar de ser una red altamente visual, se usa muy poco para ver fotos por nuestra muestra.

En promedio el 32\% consume al día entre 15 y 20 minutos para ver fotos en una red social y el $27 \%$ emplea ente 30 minutos y una hora. Es decir que cerca del $60 \%$ emplea entre 15 minutos y una hora al día para ver fotos en una red social. Y el $21 \%$ emplea entre una y tres horas al día para ver fotos en las redes.

Al igual que en el estudio anterior ya referido, el tema que más visualizan los jóvenes es "amigos" (44\%), "artistas" (18\%) y "paisajes" (7.5\%). Lo que menos consumen son "noticias nacionales" ( $0.0 \%$ como opción más relevante), "política" $(1.0 \%)$ y "movimientos ciudadanos" (1.0\%). Esto también es significativo porque expresa un completo desapego al consumo de imágenes con fines informativos, políticos o de cambio social, podríamos decir que se hace un uso apolítico al momento de consumir imágenes en las redes sociales mediante el móvil, y se refuerza la práctica de fortalecer los vínculos de amistad y vida privada. 
Lo que más se hace con las fotos que se ven en el móvil es "compartirlas con amigos (36\%) y "guardarlas en el dispositivo (35\%). Llama la atención que las fotos que les gustan las guardan en el dispositivo, pero también las comparten con amigos, una práctica híbrida entre kodakr y snapr.

\subsection{Socialización}

En este apartado reunimos los resultados relacionados con la socialización fotográfica, es decir, si los jóvenes comparten sus fotos, qué tipos de fotos comparten, si han sido editadas o no, si la edición busca alguna intención artística, por qué medios y con qué frecuencia lo hacen, cuál es la finalidad al compartir las fotos, qué redes sociales usan más para socializar sus fotos.

Encontramos que el $92.4 \%$ comparte sus fotos y el $82.9 \%$ lo hace mediante una red social, el $10 \%$ la sube a un blog o un perfil dedicado a la fotografía, mientras que sólo el $5 \%$ ve las fotos en la pantalla del celular con amigos y familia, y únicamente el $1.1 \%$ imprime las fotos. La red social más usada para socializar las fotos es Instagram (51\%), seguida de Facebook (35\%) y Twitter (5\%). Esto significa un aumento notable en el uso de una red social para socializar las fotos, y un cambio muy significativo en el uso de Instagram en cuanto a nuestro estudio anterior en el que Facebook era usado por el $79.7 \%$ de la muestra.

Los tipos de fotos más compartidas son "amigos" (63\%), "paisajes" (58\%), viajes (53\%), "autorretrato" (46\%); y las menos compartidas son "fiestas" (29\%), "familiares" (29\%) y "mascotas" (26\%). Cómo podemos observar la mayoría de tipos de fotos que se comparten pertenecen al ámbito privado, aunque sigue siendo significativo "amigos" sea la categoría de fotos más compartida al igual que en el estudio anterior.

La finalidad más frecuente al momento de compartir una foto en una red social es "para hacer un álbum" (34.4\%), seguida de "publicar mi trabajo como fotógrafo" (24.4\%), y "afianzar la relación con mis amigos" (22.2\%). Contrasta mucho este resultado frente al estudio anterior, en el que la principal finalidad al compartir una foto en un red social era "compartirlas con amigos" (91\%). Aunado a esto, destaca 


\section{ARTÍCULOS DE INVESTIGACIÓN}

el dato de que el $73 \%$ de las fotos que se comparten han sido editadas previamente y un $67 \%$ de los jóvenes lo hacen con una "intención artística".

La mayor frecuencia para compartir una foto en una red social es "un par de horas después" (43.3\%), seguida de "inmediatamente después de tomarla" (18.8\%), y "al otro día de haberla tomado" (15.5\%). Esto significa que el $77.6 \%$ de los jóvenes comparten sus fotos a más tardar un día después de haberlas tomado. Un cambio significativo respecto a nuestro estudio anterior, en el que el 53.4\% compartía sus fotos "un par de días después".

El $60.2 \%$ tiene una página personal en una red social dedicada a la fotografía, siendo Instagram la red más empleada (65.1\%), seguida de Tumblr (12.1\%), Flic$\mathrm{kr}(6 \%)$ y Pinterest $(4.5 \%)$. Es un dato significativo que en suma, el $87.7 \%$ de la muestra tiene un perfil dedicado para subir fotos en una red social dedicada a la fotografía.

La mayoría agrega un comentario a las fotos que sube a una red social (84.9\%), y el $60.2 \%$ agrega un comentario a las fotos que recibe. El índice de participación social mediante comentarios escritos es notablemente alto.

\subsection{Privacidad}

En esta sección exploramos si los jóvenes comparten fotos de su vida privada y qué temas sí publicarían y cuáles no. Encontramos que el 56.9\% de la muestra sí comparte fotos de su vida privada (reuniones familiares, vida en pareja, fiestas, viajes, fotos de su casa, niños conocidos).

Los temas que los jóvenes están más dispuestos a compartir son "viajes" (80.4\%), "situaciones divertidas de mis amigos" (61.9\%) y "autorretratos" (60.8\%). Los temas que no publicarían en una red social son "de mí en estado de ebriedad (84.6\%), “sexo" (83.5\%) y "de mis amigos en situaciones comprometedoras" (78\%).

A pesar de que aparentemente cuidan la publicación de temas "privados", sí están dispuestos a publicar viajes, amigos y autorretratos. La comprensión de lo 
Fotografía móvil y redes sociales: Prácticas de producción y socialización... 15 ARTíCULOS DE INVESTIGACIÓN

"privado" parce limitarse a la sexualidad, estado de ebriedad y situaciones consideradas comprometedoras. Se trata más de un tema moral y de cómo los verían los demás, que de cuidar la publicación de la vida privada, y en ella, otros temas que también están dispuestos a publicar, como "pareja" (52.1\%), "en la fiesta" $(53.2 \%)$, "familiares" (47.8\%).

\subsection{Derechos de autor}

En esta sección exploramos qué saben los jóvenes sobre derechos de autor, si leen los contratos de los perfiles que usan en las redes sociales y si saben qué derechos ceden al momento de publicar una foto en una red.

Encontramos que el $83.8 \%$ no lee los contratos al crear un perfil en una red social. El 64.5\% no conoce las normas sobre derechos de autor de la red social que usa. Y el 55.9\% no sabe qué derechos cede o pierde cuando sube una foto a una red social.

El 46.2\% de la muestra cree que pierde "la propiedad intelectual" de sus fotos al subirlas a una red social, el $34.4 \%$ afirma que "cede sus datos personales", y el $33.3 \%$ sabe que cede los "derechos patrimoniales" de sus fotos. El $20.4 \%$ cree que pierde "la posibilidad de recuperar la imagen", el 19.3\% afirma que "no cede ningún derecho" y el 13.9\% cree que "se ceden todos los derechos". Como podemos observar, existe una enorme desinformación y apatía sobre qué derechos se ceden al subir una foto en una red social y ante la necesidad de leer los contratos.

Es notablemente alto el índice de jóvenes que no leen los contratos y que piensan que se puede ceder la "propiedad intelectual", la cual es inalienable.

\section{Discusión}

Los resultados de este estudio revelan que los jóvenes mexicanos de la muestra tienen competencias tecnológicas digitales que los acercan más a los snaprs, aunque mantienen prácticas culturales fotográficas que todavía pertenecen a la cultura kodak.

DOI: ri14.v15i1.999 | ISSN: 1697-8293 | Año 2017 Volumen 15 N$^{\circ} 1$ | ICONO14 


\section{ARTÍCULOS DE INVESTIGACIÓN}

Es decir, por una parte estos jóvenes poseen toda una arquitectura tecnológica, smartphones, acceso a Internet, computadoras y redes sociales, tomas fotos con una frecuencia elevada y las comparten en red de manera casi inmediata. Pero por otra parte, todavía guardan sus fotos en una memoria, no sólo las dejan en la red, y los temas que más fotografían y comparten están en la esfera de lo privado, principalmente centrados en amigos, viajes y paisajes, que tienden a reforzar los lazos afectivos y son temas comunes en la cultura kodak.

Podríamos afirmar que las muestra de jóvenes universitarios mexicanos del presente estudio tiene una cultura fotográfica híbrida, con una tendencia más inclinada hacia la cultura snapr y menos hacia la cultura kodak.

\subsection{Producción}

Es muy significativa la aparición de Instagram, que se ha consolidado como la red social más importante para compartir fotos, por encima de Facebook. Instagram representa un cambio paradigmático en la forma de producir, retocar y compartir fotografías mediante el teléfono móvil.

Mayoritariamente la muestra usa IPhone y paga un promedio de 40 dólares al mes, lo que indica que hay una inversión económica alta en el smartphone, que está relacionada con la calidad de la cámara y que es un dispositivo relevante en su producción fotográfica.

También encontramos dos tendencias significativas, la mayoría de los jóvenes comparte sus fotos en una red social, para compartir su experiencia y con el fin de crear un álbum en una red especializada en fotografía; y a la mayoría le interesa retocar sus fotos antes de subirlas, comentarlas y darles un valor artístico. Este es una práctica claramente snapr.

\subsection{Consumo}

El consumo está centrado en amigos, artistas y paisajes, principalmente mediante Instagram, dedicando entre 15 minutos y una hora al día para ver fotos. A 
pesar de ello, se usan muy poco redes especializadas en fotografía como Flickr o 500 pixeles, lo cual denota una tendencia a la cultura snapr pero todavía alejada de una práctica especializada en fotografía profesional.

Como se ha comentado, llama la atención que las fotos que les gustan las guardan en la memoria del celular, una práctica más próxima a la cultura kodak en la que el almacenamiento de fotos se consideraba una práctica necesaria. Por el contrario en la cultura snapr los fotógrafos guardan todas sus fotos en una red o una nube.

Encontramos también un total desapego a consumir y fotografiar temas de carácter social, político y relacionados con movimientos sociales. Esto indica una cultura kodak todavía arraigada y una posición ideológica apática al momento de usar la cámara del móvil y las redes sociales con fines políticos.

\subsection{Socialización}

Los jóvenes demuestran una alta competencia tecnológica al momento de usar la cámara y compartir las fotografías mediante una red social. La gran mayoría comparte sus fotos en una red social con una alta frecuencia. Sin embargo, la socialización sigue estando realizada con los amigos, con temas relacionados con la vida privada, vemos esto como una práctica híbrida entre snapr y kodakr.

Otros indicios de una tendencia snapr son que existe la motivación al compartir fotos de crear un álbum fotográfico en línea, que la gran mayoría tienen un perfil dedicado a la fotografía en una red social, y que también la mayoría comenta las fotos que consume y que comparte.

\subsection{Privacidad}

Los jóvenes de la muestra tienen una cultura snapr en cuanto al tratamiento de la privacidad, están dispuestos a publicar un gran abanico de temas relacionados con su vida familiar, amigos, pareja, viajes, fiestas. 


\section{ARTÍCULOS DE INVESTIGACIÓN}

Sin embargo, los temas relacionados con la sexualidad y situaciones comprometedoras siguen representando una frontera moral para su publicación, al igual que en el estudio anterior.

En resumen, podemos afirmar que los jóvenes tienen una cultura snapr sobre la privacidad, aunque todavía con limitaciones morales sobre la publicación de la sexualidad.

\subsection{Derechos de autor}

Los jóvenes de la muestra tienen una clara cultura kodak en cuanto a derechos de autor se refiere, una escasa preocupación por conocer los términos de los contratos que firman al crear un perfil en la red social que usan.

A pesar de que los jóvenes tiene acceso a una arquitectura digital amplia, todavía no adquieran el conocimiento sobre derechos de autor y privacidad que establecen los contratos de las redes sociales, y específicamente sobre los derechos sobre las fotografías publicadas.

\section{Conclusiones}

El presente estudio revela una clara tendencia en los jóvenes universitarios que estudian Comunicación y Medios Digitales, y Animación y Arte Digital en el Tecnológico de Monterrey - Ciudad de México, a adquirir progresivamente una cultura snapr frente a una cultura kodak (Miller y Edwards, 2007). Esta tendencia está centrada en competencias tecnológicas y prácticas de producción, consumo y socialización en convergencia con las posibilidades que ofrecen los dispositivos móviles con acceso a Internet y las redes sociales, como el compartir las fotos en tiempo real, retocarlas, hacer perfiles, álbumes y comentarlas.

Sin embargo, encontramos que existen prácticas de la cultura kodak más centradas en las temáticas relacionadas con el reforzamiento de la vida privada y los amigos, frente a un casi nulo interés por otros temas, como la vida social o política. 
También encontramos una cultura kodak en cuanto al conocimiento sobre derechos de autor y condiciones de uso de las redes sociales que usan los jóvenes a través del smartphone, demostrando muy poco conocimiento sobre los derechos de autor en la redes y desinterés en leer los contratos.

En algunos aspectos podemos afirmar que existen prácticas culturales híbridas, entre snapr y kodak, como el compartir las fotos casi en tiempo real pero con el temas de la vida privada, y comentar las fotos que les gustan en la red, compartirlas, pero también guardarlas en la memoria del celular.

Las prácticas de producción, consumo, socialización y derechos de autor que revela el presente estudio, denotan que a pesar de contar con acceso a una arquitectura digital amplia y a una formación sobre temas de imagen, comunicación y fotografía, los jóvenes de la muestra presenta anclajes culturales del tipo kodak, aunque con algunos importantes indicios que marcan una tendencia hacia la cultura snapr de manera lenta y progresiva.

Los anclajes tipo "kodak" están centrados en el registro de la vida privada, aunque con un cambo significativo al momento de la publicación de esa vida privada en redes sociales, con un creciente uso de Instagram.

Podemos concluir que las prácticas digitales de la fotografía móvil en la muestra de jóvenes universitarios estudiada, presentan un giro notable en el uso de redes sociales dedicadas a la fotografía, aplicaciones móviles, con prácticas de socialización en tiempo real, con una tendencia a apropiarse cada vez más del paradigma digital en la cultura fotográfica snapr, aunque de manera lenta y perdiendo gradualmente los principales rasgos de la cultura kodak, principalmente en la preservación y captura de la vida privada, la socialización con amigos y la ignorancia sobre derechos de autor al momento de usar las redes sociales.

Los retos de los siguientes estudios en México, podrán estar centrados en conocer las prácticas fotográficas en dispositivos móviles, en muestras de poblaciones más amplias y menos favorecidas en cuanto a acceso a una arquitectura digital, dispositivos y conexión a redes sociales. 


\section{ARTÍCULOS DE INVESTIGACIÓN}

\section{Referencias}

AMIPCI (2015). $11^{\circ}$ Estudio sobre los hábitos de los usuarios de Internet en México 2015. (https://goo.gl/9apNAs) (2015-09-25).

Araya, D., Breindl, Y., Houghton, T. (2011). Nexus: New Intersections in Internet Research. New York: Peter Land Publishing, Inc. (https://goo.gl/QHYFRw) (2015-11-2).

Bañuelos, J. (2011). Photography 2.0: Competences and cultural practices. Razón y Palabra. Recuperado de ISSN 1605-4806 (https://goo.gl/KQoBga) (2015-11-2). Castells, M. (No. 6, 2011). "Democracy in the age of the Internet". Transfer: Journal of contemporary culture, pp. 96-103. (http://goo.gl/ucM3za) (2016-05-20)

Castells, M. (2006) La Sociedad Red. La era de la Información, economía, sociedad y cultura, Madrid: Alianza Editorial.

Castells, M. (2007). Comunicación Móvil y Sociedad. Madrid: Ariel.

Castells, M. (2009). Comunicación y Poder. Madrid: Alianza.

Chalfen, R. (1987). Snapshot versions of life. Bowling Green, Ohio: Bowling Green State University Popular Press.

David, G. (2014). The selfie research network. (http://goo.gl/9sK55e) (2016-4-11). Hand, Martin, (2012). Ubiquitous Photography. Cambridge: Polity Press (https:// goo.gl/Ueo7hx) (2016-2-10).

Hjorth, L. (2007) 'Snapshots of Almost Contact: The Rise of Camera Phone Practices and a Case Study of Seoul, Korea', Continuum: Journal of Media and Cultural Studies, Vol.21, No.2, June, pp.227-38. doi: http://dx.doi. org/10.1080/10304310701278140

Hjorth, L. (2009). Photo Shopping: A snapshot on camera phone practices', Knowledge, Technology \& Policy journal, 22(3): 157-159. doi: 10.1007/s12130009-9085-9

Hjorth, L. (2010). Photoshifting: art practice, camera phones and social media, Photofile 89. (http://goo.gl/AfQP2F) (2016-03-15)

LSE. (2013) Mobile VIsual References. Department of Media and Communications. (http://goo.gl/t0m8hE) (2016-03-14).

Manovich, L. (2013). The Algorithms of Our Lives. The Chronicle of Higher Education, December 16. (http://goo.gl/T3J4uh) (2016-04-24). 
Manovich, L. (2012). Media Visualization: Visual Techniques for Exploring Large Media Collections. Media Studies Futures, ed. Kelly Gates. Blackwell, 1-21. (http://goo.gl/3xxPGC) (2016-04-21).

Manovich, L. (2009). Cultural Analytics: Visualizing Cultural Patterns in the Era of 'More Media'. DOMUS. (http://goo.gl/nxYwnZ) (2016-03-20).

Miller, A., Edwards, K. (2007), Give and take: A study of consumer photo-sharing culture and practice, Proceedings of the SIGCHI Conference on Human Factors in Computing Systems, 347-356. doi: 10.1145/1240624.1240682

Miller-Ott, A. E., Kelly, L., \& Duran, R. L. (2012). The Effects of Cell Phone Usage Rules on Satisfaction in Romantic Relationships. Communication Quarterly, 60(1), 17-34. doi: 10.1080/01463373.2012.642263

Nov, 0., Naaman, Mor., Ye, Ch. (2009). Analysis of participation in an online photosharing community: A multidimensional perspective. Journal of the American Society. Information Science and Technology, 555-566. doi: 10.1002/asi.21278

Nov, 0., Ye, Ch. (2008), Community photo sharing: Motivational and structural antecedents. Association for Information Systems, New York: New York University. (http://goo.gl/iAu73j) (2016-05-2016).

Palfrey, J. \& Gasser, U. (2008). Born digital.Understanding the first generation of digital natives. New York: Basic Books.

Prensky, M. (octubre, 2001). Digital Natives, Digital Immigrants. In On the Horizon (MCB University Press, Vol. 9 No. 5, October 2001). (http://goo.gl/40Yb) (201604-10).

Sarvas, R., Frohlich, D. (2011). From Snapshots to Social Media - The Changing Picture of Domestic Photography. New York: Springer London Dordrech. (http://goo.gl/0uhM3K) (2016-04-11)

Thompson, J. (2005). The new visibility, Theory, Culture \& Society December 2005 vol. 22 no. 6 31-51, doi: 10.1177/0263276405059413

Van House, N. and Davis, M.(2005) The Social Life of Cameraphone Images, Proceedings of the Pervasive Image Capture and Sharing: New Social Practices and Implications for Technology Workshop (PICS 2005) at the Seventh International Conference on Ubiquitous Computing (UbiComp 2005) Tokyo, Japan. (http://goo.gl/xGCC6H) (2016-04-12) 


\section{ARTÍCULOS DE INVESTIGACIÓN}

Van House, N., Davis, M., Ames, M., Finn, m. and Viswanathan, V. (2005) The Uses of Personal Networked Digital imaging: An Empirical Study of Cameraphone Photos and Sharing, Proceedings of CHI 2005, Portland, Oregon, April, ACM Press, 1853-1856. doi: 10.1145/1056808.1057039

Van Dijck, J. (2008). Digital photography: communications, identity, memory, Visual Communication, Vol. 7, No. 1, 57-76. doi: 10.1177/1470357207084865 Yan, S. (2015). Encyclopedia of Mobile Phone Behavior. USA: Information Sicence Reference. (https://goo.gl/H4pk6o).

\section{Agradecimiento}

Agradezco a los alumnos de las carreras de Ciencias de la Comunicación y Animación-Arte Digital, inscritos en la materia de Fotografía e Imagen Digital 201415, del Tecnológico de Monterrey-Campus Ciudad de México, por haber contribuido con sus respuestas, en este estudio. 